\title{
KNOWLEDGE ON HYPOGLYCEMIA AMONG PATIENTS WITH DIABETES MELLITUS
}

\author{
THENMOZHI P1*, VIJAYALAKSHMI M²
}

${ }^{1}$ Department of Nursing, Saveetha College of Nursing, Saveetha University, Chennai, Tamil Nadu, India. ${ }^{2}$ Department of Nursing, Saveetha College of Nursing, Saveetha University, Chennai, Tamil Nadu, India. Email: thenmozhi.sethu@gmail.com

Received: 02 September 2017, Revised and Accepted: 12 October 2017

ABSTRACT

Objective: The objective of the study is to assess the level of knowledge on hypoglycemia among patients with diabetes mellitus in the rural community. Hypoglycemia is an acute complication of diabetes mellitus. The recognition of hypoglycemia and immediate treatment of hypoglycemia should be known by all the diabetic patients so that treatment of hypoglycemia may not be delayed, need for hospitalization could be avoided, and life-threatening complications due to hypoglycemia may be prevented.

Methods: A cross-sectional research design was adopted with 60 samples who met the inclusion criteria in the rural community in India. Structured interview method was used to collect the data. Data were analyzed by descriptive and inferential statistics.

Result: Of 60 samples, 38 (63.33\%) had inadequate knowledge, 12 (20\%) of them had moderately adequate knowledge, and 10 (16.67\%) of them had adequate knowledge. There is a significant association between the age and type of treatment at the level of $\mathrm{p}<0.05$ with the level of knowledge on hypoglycemia.

Conclusion: The study findings emphasized that majority of the patients with diabetes mellitus do not have the knowledge on hypoglycemia. The health-care professional has an important role in educating diabetics on hypoglycemia so that hypoglycemic episodes and morbidity could be reduced or prevented.

Keywords: Diabetes mellitus, Hypoglycemia, Knowledge, Insulin, Oral hypoglycemic drugs.

(C) 2018 The Authors. Published by Innovare Academic Sciences Pvt Ltd. This is an open access article under the CC BY license (http://creativecommons. org/licenses/by/4. 0/) DOI: http://dx.doi.org/10.22159/ajpcr.2018.v11i1.22336

\section{INTRODUCTION}

Hypoglycemia is an acute complication of diabetes mellitus, and it is the medical term for a state produced by a lower than normal level of blood glucose [1]. Diabetes mellitus is a metabolic disorder characterized by elevated blood glucoselevels and disturbances in carbohydrates, fats, and protein metabolism and associated with metabolic complications that can subsequently lead to premature death [2]. The term hypoglycemia literally means "under-sweet blood." It occurs when the blood glucose falls to $<40-50 \mathrm{mg} / \mathrm{dl}$ which may endanger patient's life as well as other person's lives. It can be caused by too much insulin intake or oral hypoglycemic agents, too little food, or excessive physical activity [3]. Diabetes medications including insulin and sulfonylureas are among the most common causes of hypoglycemia in diabetic subjects [4]. The longer-acting sulfonylureas such as glibenclamide and chlorpropamide are associated with more severe hypoglycemia than the shorter-acting drugs [5]. Metformin was the most frequent used oral hypoglycemic agents $(66.4 \%)$ followed by sulfonylurea and the most prevalent combination therapy was metformin/glibenclamide regimen (28.5\%). The majority of patients treated with metformin at the time when they were diagnosed with diabetes (45.3\%). Hypoglycemic episodes were most commonly reported adverse events with insulin and gastric upset with oral hypoglycemic agents. $60.3 \%$ of the patients didn't follow regular blood glucose checkup [6]. Several reports reveal that various pharmacological agents like metformin, rosiglitazone etc., which have wide ranging side effects, including weight gain, hypoglycemia and risk of coronary heart disease [7]. Occasional episodes of hypoglycemia with metformin, as the most commonly used antidiabetic drug, are reported when an imbalance between food intake and dose of metformin is presented [8]. Hypoglycemia is a condition characterized by sweating, tremor, tachycardia, palpitation, nervousness, hunger, confusion, slurred speech, emotional changes, double vision, drowsiness, sleeplessness, and often self-diagnosed [1,3]. In type 2 diabetes, one longitudinal cohort study in elderly patients revealed that severe hypoglycemia episodes are associated with an increased risk of dementia in this population, although the impact of mild episodes on dementia risk remains unknown [9]. A recent study found that severe hypoglycemia causes brain damage in cortex and the hippocampus regions and the extent of damage was closely correlated to the presence of seizure-like activity. The results were indicative of elevation of the sensitivity of the cortex to the damaging effects following an episode of severe hypoglycemia [10]. Hypoglycemia is a common problem in old people with diabetes. Aging modifies the cognitive, symptomatic, and counter-regulatory hormonal responses to hypoglycemia [11]. The effect of aging on the increased risk of unawareness or severe episodes of hypoglycemia has also been recognized [12]. Diabetes mellitus is treating with synthetic drugs, namely, sulfonylureas, thiazolidinediones, glinide, and metformin, but they retain many side effects [13].

Most of the patients who lack of knowledge to recognize all these symptoms may lead to delayed treatment which causes even death. The individual fails to become aware of hypoglycemia due to lack of knowledge to recognize these symptoms and can result in prolonged hypoglycemia with consequent brain injury, seizure, and loss of consciousness because the brain is dependent on the blood glucose for energy necessary for its activity and cannot survive more 6 min without glucose. Severe hypoglycemia is usually associated with increased mortality and impaired cognitive function and affects patient's quality of life.

The American Diabetes Association defines the hypoglycemia as "any abnormally low plasma glucose concentration that exposes the subject to potential harm," and proposes a threshold of $<70 \mathrm{mg} \%$ [14]. The spectrum of symptoms depends on duration and severity of hypoglycemia and varies from autonomic activation to behavioral changes to altered cognitive function to seizures or coma 
[15]. The short- and long-term complications include neurologic damage, trauma, cardiovascular events, and death. There can be a sixfold higher incidence of death, increased costs of medical care, and loss of productivity due to hypoglycemia [16]. Apart from patient-related factors such as lifestyle and comorbid conditions of the patients, various other factors such as choice, dose, timing, and combination of antidiabetic drugs together with simultaneous use of other interacting drugs can increase the risk of hypoglycemia in diabetics.

The immediate treatment of hypoglycemia should be known by all the diabetic patients so that treatment of hypoglycemia may not be delayed and need for hospitalization could be avoided. Illiterate patients and elderly patients with dementia must be more educated about hypoglycemia. Thus, improving patient skills self-management, selfmonitoring of sugar, and adjustments of dose based on requirements can reduce the risk of hypoglycemia. Awareness on hypoglycemia symptoms and its early management was average among diabetics. Initiation of home care followed by hospitalized care is the most ideal way to prevent severe spells of hypoglycemia. The healthcare professional has an important role in educating diabetics on hypoglycemia so that hypoglycemic episodes and morbidity could be reduced or prevented.

The investigator felt that the number of diabetes patients is increasing and the disease is now prevalent in all age groups in India. Diabetes mellitus is one of the important public health issues and challenging the world in the $21^{\text {st }}$ century. The prevalence of diabetes has reached epidemic proportions in most populations. According to the UN World Health Organization (WHO), more than 220 million people worldwide have diabetes, from which more than $70 \%$ live in low- and middleincome countries. It is expected that the number of diabetic subjects grows to 366 million by 2030, a figure that is more than twice the number in 2000. Epidemiologic evidence suggest that unless effective preventive measures are implemented the global prevalence will continue to rise [17]. It is seen that patients with diabetes mellitus have lack of knowledge about the disease condition, especially diabetes mellitus and its management moreover about hypoglycemia. With this background, the investigators felt it necessary to conduct a study to assess the level of knowledge on hypoglycemia in diabetes patients.

\section{METHODS}

A non-experimental cross-sectional research design was adopted to assess the level of knowledge on hypoglycemia with 60 samples with diabetes mellitus in the rural community. The samples were selected by convenient sampling technique who met the inclusion criteria. People with diabetes for 1 year and above and on the treatment of insulin or OHA or both were included in the study. The patients who consented in written form to participate were informed about the purpose of the study. The tool used for the study was demographic variables and dichotomous questionnaire. Structured interview schedule was used to collect the data on one to one basis. They were assured about their confidentiality and anonymity throughout the study. The collected data prepared for analysis using Microsoft Excel and were analyzed using descriptive and inferential statistics. $p<0.05$ were considered statistically significant.

\section{RESULTS}

\section{Distribution of demographic variables}

There are 60 samples were recruited for the study. Of 60 samples, a majority $(76.67 \%)$ of them were in the age group between 51 and 60 years, and $50 \%$ of them were male and $50 \%$ of them were female. Regarding educational status, $33.33 \%$ were illiterate, remaining of them were completed till secondary school education, and most of them have the diabetes mellitus with the duration between 4 and 10 years. $50 \%$ of them were on the treatment of insulin, and only $10 \%$ of them were on the treatment of both insulin and oral hypoglycemic agents as summarized in Table 1.
Level of knowledge on hypoglycemia

Among 60 samples, 38 (63.33\%) had inadequate knowledge, 12 (20\%) of them had moderately adequate knowledge, and 10 (16.67\%) of them had adequate knowledge as shown in Fig. 1.

Mean and standard deviation of level of knowledge on hypoglycemia among patients with diabetes mellitus

The mean score of knowledge on causes of hypoglycemia was 3.91 with 1.73 standard deviation. Mean and standard deviation of knowledge on signs and symptoms was 3.82 with 2.31. The mean score of knowledge on first aid measures and prevention of hypoglycemia was 6.5 with 1.21 standard deviation, and an overall mean score of the level of knowledge on hypoglycemia was 14.13 with 2.18 standard deviation as shown in Table 2.

Association between the level of knowledge on hypoglycemia and selected sociodemographic variable among patients with diabetes mellitus

Chi-square test reveals that there is a significant association between the age and type of treatment at the level of $p<0.05$ with the level of knowledge on hypoglycemia in Table-3.

Table 1: Distribution of sociodemographic variables of study participants

\begin{tabular}{llll}
\hline S. No. & $\begin{array}{l}\text { Sociodemographic } \\
\text { variable }\end{array}$ & Classification & Frequency (\%) \\
\hline 1. & Age in years & $30-40$ & - \\
& & $41-50$ & $2(3.33)$ \\
& & $51-60$ & $46(76.67)$ \\
2. & Sex & Male & $12(20)$ \\
& & Female & $30(50)$ \\
3. & Education & Illiterate & $20(33.33)$ \\
& & Primary school & $30(50)$ \\
& & High school & $8(13.34)$ \\
& & Higher & $2(3.33)$ \\
4. & Secondary & \\
& Duration of & $1-3$ years & $12(20)$ \\
& diabetes mellitus & 4-6 years & $20(33.33)$ \\
& & $7-10$ years & $20(33.33)$ \\
& & 11 years and & $8(13.34)$ \\
& & above & \\
5. & Type of treatment & Insulin & $30(50)$ \\
& & Oral & $24(40)$ \\
& & hypoglycemic & \\
& & agents & \\
& & Both & $6(10)$ \\
\hline
\end{tabular}

Table 2: Mean and standard deviation of level of knowledge on hypoglycemia among patients with diabetes mellitus

\begin{tabular}{ll}
\hline Level of knowledge on hypoglycemia & Mean \pm SD \\
\hline Causes of hypoglycemia & $3.91 \pm 1.73$ \\
Signs and symptoms of hypoglycemia & $3.82 \pm 2.31$ \\
First aid measures and prevention of hypoglycemia & $6.5 \pm 1.21$ \\
Overall knowledge & $14.13 \pm 2.18$ \\
\hline
\end{tabular}

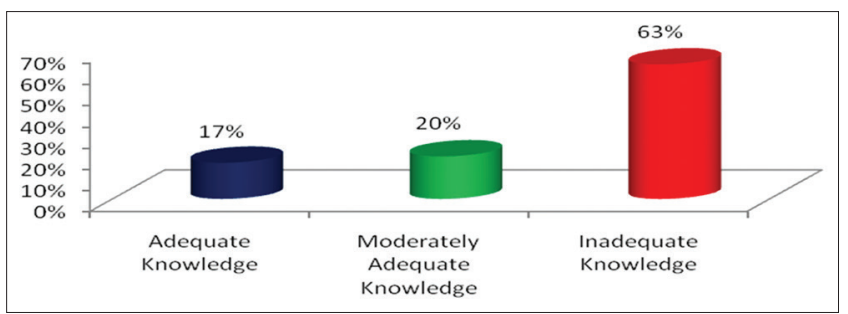

Fig. 1: Distribution of level of knowledge on hypoglycemia 


\section{DISCUSSION}

Hypoglycemia is one among the leading causes for emergency and is the most common and easily preventable endocrine emergency. With increasing incidence of diabetes, there is a risk for an increase in the incidence of hypoglycemia though with various treatment modalities available to control blood glucose level. With this background, the present study was conducted with 60 samples to assess the level of knowledge on hypoglycemia among the people with diabetes mellitus who are residing in the rural community. The findings showed thatout 60 samples, $38(63.33 \%)$ had inadequate knowledge, $12(20 \%)$ of them had moderately adequate knowledge, and 10(16.67\%) of them had adequate knowledge. The findings are consistent with the study conducted by Shriraam et al. and found that that $66.1 \%$ of diabetic patients had good knowledge on hypoglycemia; however, educational status of the client is associated with the level of knowledge [18]. The study by Pai and George revealed that $54 \%$ had average awareness about symptoms of hypoglycemia and $49 \%$ patients preferred taking glucose powder or sugar with water as an immediate measure and also the awareness was higher among literate subjects about hypoglycemia symptoms [19]. In this research, educational status and being a member of diabetic association were found to be positively associated with knowledge and practice [20]. The findings of the study indicated that many respondents $(74.5 \%)$ were able to identify at least one correct warning sign, but $32 \%$ could not state any correct treatment measures. Most of the studied sample does not know what does hypoglycemia means [21]. Slightly less than the half of cases (49\%) had a poor knowledge score and the only variable significantly associated with poor knowledge score was the education level $(\mathrm{p}=0.001)$ and described by the study of Tawfeeq et al. [22]. Educational status and being a member of diabetic association were found to be positively associated with knowledge and practice. Respondents who attained primary education, secondary education, college, and above were found to be more likely to have good knowledge compared with respondents who did not have formal education [20]. Even though wearing an identification band is need for diabetic patient, only $13.5 \%$ had a practice of carrying identification card in this study [23]. These studies are congruent with the present study, and when compared with the present study findings, educational status of the client plays an important role in taking care of themselves and also people with diabetes mellitus have knowledge on self-care management, but still they had very poor knowledge on hypoglycemia. Many of them had experienced the symptoms of hypoglycemia but may not know that this is due to hypoglycemia caused by drug and improper diet, and they do not know the first aid measures to treat the hypoglycemia. One of the reasons for this inadequate knowledge and lack of awareness on hypoglycemia is due to low educational status.

\section{CONCLUSION}

The study findings concluded that there is a lack of knowledge on hypoglycemia among patients with diabetes mellitus. Health-care

Table 3: Association between the level of knowledge on hypoglycemia and selected sociodemographic variable among patients with diabetes mellitus

\begin{tabular}{|c|c|c|c|c|c|}
\hline \multirow[t]{2}{*}{ S. No. } & \multirow[t]{2}{*}{ Sociodemographic variables } & \multicolumn{3}{|c|}{ Level of knowledge } & \multirow[t]{2}{*}{ Chi-square } \\
\hline & & Inadequate & Moderately adequate & Adequate & \\
\hline \multirow[t]{5}{*}{1.} & Age in years & & & & \\
\hline & $30-40$ & 0 & 0 & 0 & $\begin{array}{l}\chi^{2}=20.73 \\
d f=6 \\
p<0.05 \\
S\end{array}$ \\
\hline & $41-50$ & 4 & 0 & 0 & \\
\hline & $51-60$ & 34 & 6 & 8 & \\
\hline & $>61$ & 0 & 6 & 2 & \\
\hline \multirow[t]{3}{*}{2.} & Sex & & & & \\
\hline & Male & 20 & 6 & 4 & $\begin{array}{l}\chi^{2}=1.88 \\
d f=2 \\
p<0.05 \\
\text { NS }\end{array}$ \\
\hline & Female & 18 & 6 & 6 & \\
\hline \multirow[t]{5}{*}{3.} & Education & & & & \\
\hline & Illiterate & 18 & 6 & 4 & $\begin{array}{l}\chi^{2}=3.79 \\
d f=6 \\
p<0.05 \\
\text { NS }\end{array}$ \\
\hline & Primary school & 14 & 2 & - & \\
\hline & High school & 4 & 4 & 4 & \\
\hline & Higher secondary & 2 & 0 & 2 & \\
\hline \multirow[t]{5}{*}{4.} & Duration of diabetes mellitus & & & & \\
\hline & $1-3$ years & 6 & 4 & 4 & $\begin{array}{l}\chi^{2}=5.22 \\
\mathrm{df}=6 \\
\mathrm{p}<0.05 \\
\text { NS }\end{array}$ \\
\hline & $4-6$ years & 18 & 2 & - & \\
\hline & $7-10$ years & 10 & 2 & - & \\
\hline & 11 years and above & 4 & 4 & 4 & \\
\hline \multirow[t]{4}{*}{5.} & Type of treatment & & & & \\
\hline & Insulin & 14 & 6 & 4 & $\begin{array}{l}\chi^{2}=38.01 \\
d f=4 \\
p<0.05 \\
S\end{array}$ \\
\hline & Oral hypoglycemic agents & 18 & 4 & 2 & \\
\hline & Both & 6 & 2 & 4 & \\
\hline
\end{tabular}

S: Significant, NS: Not significant 
professionals have a major role in educating clients with diabetes mellitus about hypoglycemia risk factors, recognition of symptoms of hypoglycemia, first aid measures of hypoglycemia, blood glucose monitoring, and selection of appropriate regimens, thereby minimize the risk of hypoglycemia, and prevent the potential complications of hypoglycemia.

\section{ACKNOWLEDGMENT}

The authors would like to thank all the participants who accept to be involved in the research study.

\section{REFERENCES}

1. Chintamani, Mani M. Lewi's Medical Surgical Nursing. $1^{\text {st }}$ ed. India: Reed Elsevier India private Ltd., Publication; 2011. p. 766-86.

2. Jain R, Jain P, Jain P. A review on treatment and prevention of diabetes mellitus. Int J Curr Pharm Res 2016;8:16-8.

3. Hinkle JL. Brunner and Siddarth's Textbook of Medical-Surgical Nursing. $13^{\text {th }}$ ed. Philadelphia, PA: Wolters Kluwer Health Publication; 2014. p. $862-5$

4. Malouf R, Brust JC. Hypoglycemia: Causes, neurological manifestations, and outcome. Ann Neurol 1985;17:421-30.

5. Stahl M, Berger W. Higher incidence of severe hypoglycaemia leading to hospital admission in Type 2 diabetic patients treated with long-acting versus short-acting sulphonylureas. Diabet Med 1999;16:586-90.

6. Moradi M, Mousavi S. Drug use evaluation of diabetes mellitus in nonhospitalized patients. Int J Pharm pharm Sci 2016;8:337-41.

7. Kalsi A, Singh S, Taneja N, Kukal S, Mani S. Current treatments for Type 2 diabetes, their side effects and possible complementary treatments. Int J Pharm Pharm Sci 2015;7:13-8.

8. Holstein A, Egberts EH. Risk of hypoglycaemia with oral antidiabetic agents in patients with Type 2 diabetes. Exp Clin Endocrinol Diabetes 2003;111:405-14.

9. Whitmer RA, Karter AJ, Yaffe K, Quesenberry CP Jr, Selby JV. Hypoglycemic episodes and risk of dementia in older patients with Type 2 diabetes mellitus. JAMA 2009;301:1565-72.

10. Bree AJ, Puente EC, Daphna-Iken D, Fisher SJ. Diabetes increases brain damage caused by severe hypoglycemia. Am J Physiol Endocrinol Metab 2009;297:E194-201.

11. Alagiakrishnan K, Mereu L. Approach to managing hypoglycemia in elderly patients with diabetes. Postgrad Med 2010;122:129-37.

12. Avila-Fematt FM, Montaña-Alvarez M. Hypoglycemia in the elderly with diabetes mellitus. Rev Invest Clin 2010;62:366-74

13. Rupeshkumar M, Kavitha K, Haldar PK. Role of herbal plants in the diabetes mellitus therapy: An overview. Int J Appl Pharm 2014;6:1-3.

14. Workgroup on Hypoglycemia, American Diabetes Association. Defining and reporting hypoglycemia in diabetes. A report from the American Diabetes Association Workgroup on Hypoglycemia. Diabetes Care 2005;28:1245-9.

15. Shafiee G, Mohajeri-Tehrani M, Pajouhi M, Larijani B. The importance of hypoglycemia in diabetic patients. J Diabetes Metab Disord 2012;11:17.

16. Dejager S, Schweizer A. Minimizing the risk of hypoglycemia with vildagliptin: Clinical experience, mechanistic basis, and importance in Type 2 diabetes management. Diabetes Ther 2011;2:51-66.

17. Alberti KG, Zimmet P, Shaw J. International Diabetes Federation: A consensus on Type 2 diabetes prevention. Diabet Med 2007;24:451-63.

18. Shriraam V, Mahadevan S, Anitharani M, Jagadeesh NS, Kurup SB, Vidya TA, et al. Knowledge of hypoglycemia and its associated factors among Type 2 diabetes mellitus patients in a Tertiary Care Hospital in South India. Indian J Endocrinol Metab 2015;19:378-82.

19. Pai SA, George P. Study on awareness of symptoms of hypoglycaemia and early management among patients with diabetes. IOSR J Dent Med Sci $2015 ; 14: 11-3$.

20. Gezie GN, Alemie GA, Ayele TA. Knowledge and practice on prevention of hypoglycemia among diabetic patients in South Gondar, Northwest Ethiopia: Institution based cross-sectional study. Integr Obes Diabetes 2015;1:56-60.

21. Reifegerste D, Hartleib S. Hypoglycemia-related information seeking among informal caregivers of Type 2 diabetes patients: Implications for health education. J Clin Transl Endocrinol 2016;4:7-12.

22. Tawfeeq W, Baker TY, Hatem SA, Jasem MK. Knowledge of Diabetic Patients about Hypoglycemia. Available from: http://www.iasj.net/ iasj?func=fulltext\&aId=35225. [Last Retrieved on 27 Aug 2017].

23. Gul N. Knowledge, attitudes and practices of Type 2 diabetic patients. J Ayub Med Coll Abbottabad 2010;22:128-31. 